\title{
A Dehydrogenase Activity Test for Monitoring the Growth of Streptomyces Venezuelae in a Nutrient Rich Medium
}

\author{
T. J. Burdock, M.S. Brooks* and A.E. Ghaly
}

Department of Process Engineering and Applied Science, Dalhousie University, P.O. Box 1000, Halifax, Nova Scotia, Canada B3J 2X4

\begin{abstract}
Jadomycin is a novel antibiotic that has shown activities against bacteria, yeasts and fungi as well as cytotoxic properties to cancer cells. Because of the wide range of its inhibitory actions, jadomycin shows promise as a nove antibiotic and cancer treatment drug. Streptomyces venezuelae are aerobic bacteria that are capable of producing jadomycin when shocked by alcohol in a nutrient deprived amino acid rich medium. The size of the bacterial population that is transferred from the growth medium to the production medium can significantly affect the jadomycin yield. Therefore, the number of transferred bacteria must be accurately measured. In this study, a dehydrogenase activity measurement test was developed for $S$. venezuelae using triphenyl tetrazolium chloride (TTC) to measure the cell growth and activity in maltose-yeast extract-malt extract (MYM) broth. The dehydrogenase activity was determined by measuring the visible color changes of the TTC to triphenyl formazan (TF). The test conditions which included extraction solvent, number of extractions, incubation time, incubation temperature and medium $\mathrm{pH}$ were evaluated. The results showed that the triphenyl formazan was related to the number of cells. Methanol was better able to permeate the cells and extract higher amount of TF than ethanol. The amount of TF increased with the number of extractions for both solvents. A lower medium $\mathrm{pH}$ and/or lower temperature produced the highest amount of TF. The best test conditions that produced the highest TF yield were three extractions using methanol after an incubation time of 1 hour at a temperature of $30^{\circ} \mathrm{C}$ and a medium $\mathrm{pH}$ of 6.
\end{abstract}

Keywords: Dehydrogenase; Triphenyl tetrazolium chloride (TTC); Jadomycin; Streptomyces venezuelae

\section{Introduction}

Jadomycins are a novel group of antibiotics that are produced by Streptomyces venezuelae. They exhibit biological activity against bacteria and yeast and demonstrate cytotoxicity against cancer cells [1]. $S$. venezuelae are typically grown in a nutrient rich medium of maltoseyeast extract-malt extract (MYM) broth prior to their introduction to a nutrient-deprived, amino acid-rich production medium $[2,3]$. Once transferred to the production medium, an environmental shock (ethanol or heat) is applied to induce the bacteria to produce jadomycin [4]. The size of the bacterial population that is transferred from the growth medium to the production medium can significantly affect the jadomycin yield [5]. Therefore, in order to standardize and improve the reproducibility of the jadomycin production process, the number of live bacteria that are transferred and subsequently shocked must be accurately determined.

Bacterial counts can be determined with various techniques such as plate counting [6] turbidity measurement [7], microscope enumeration [8] and dehydrogenase activity measurement (Knight et al.). The dehydrogenase activity measurement technique has the advantage over other methods in being able to quantify the number of live cells that are present in the medium [9-11] and it can be employed in a relatively short time and at a low cost [12].

The dehydrogenase activity test is based on the principle that dehydrogenase enzymes are produced by all living cells and the extent to which this enzyme group oxidizes organic matter can be related to the number of live cells present [12]. This group of enzymes transports electrons and hydrogen through a chain of intermediate electron carriers to a final electron acceptor (oxygen), resulting in the formation of water [13-16]. The activity of the co-enzymes Nicotinamide Adenine Dinucleotide (NAD) and Flavin Adenine Dinucleotide (FAD) which act as intermediate electro acceptors can be measured by the visible col- or change of a dye such as triphenyl tetrazolium chloride (TTC) [12].

The process of measuring dehydrogenase activity involves incubating the sample in the presence of triphenyl tetrazolium chloride and an electron-donating substrate[12]. In its oxidized form, TTC is colourless, but in the presence of dehydrogenase enzymes TTC is reduced to triphenyl formazan (TF), a red water insoluble compound [12, 17-19]. The TF is retained within microbial cells and can result in highly coloured colonies when grown on agar plates [18]. The mechanism of the process is summarized in Figure 1.

Triphenyl formazan can be extracted from cells using a solvent and the concentration is determined colorimetrically by measuring the optical density at $484 \mathrm{~nm}$ [12]. The use of a dehydrogenase activity measurement test using TTC to measure the quantity of living cells has great potential as a quick tool for determining the optimal time to shock a population of $S$. venezuelae and start the production of jadomycin. However, the amount of TF extracted depends on number of extractions, extraction solvent, incubation time, incubation temperature, and medium $\mathrm{pH}$ [20].The purpose of this study was to develop a dehydrogenase activity measurement test for $S$. venezuelae that could be used to quantify the live bacterial cells. The specific objectives were to: (a) investigate the applicability of the TTC-test for measuring dehydrogenase activity in S. venezuelae and (b) determine the ideal test

*Corresponding authors: Su-Ling Brooks, Associate Professor, Department of Process Engineering and Applied Science, Dalhousie University, Halifax, Nova Scotia, Canada B3J 2X4, Tel: (902) 494-6482; Fax: (902) 420-7639; E-mail: SuLing.Brooks@dal.ca

Received January 18, 2011; Accepted April 26, 2011; Published June 11, 2011

Citation: Burdock TJ, Brooks MS, Ghaly AE (2011) A Dehydrogenase Activity Test for Monitoring the Growth of Streptomyces Venezuelae in a Nutrient Rich Medium. J Bioprocess Biotechniq 1:101 doi:10.4172/2155-9821.1000101

Copyright: (c) 2010 Burdock TJ, et al. This is an open-access article distributed under the terms of the Creative Commons Attribution License, which permits unrestricted use, distribution, and reproduction in any medium, provided the original author and source are credited. 
conditions (extraction solvent, number of extractions, incubation time, incubation temperature and medium $\mathrm{pH}$ ).

\section{Experimental Materials}

\section{Reagents}

Tris (hydroxymethyl-aminomethane) buffer was used to control the $\mathrm{pH}$ of the samples and triphenyl tetrazolium chloride (TTC) was the tetrazolium salt used for the dehydrogenase test. A TTC-glucose reagent ( $1 \mathrm{~g}$ glucose and $2 \mathrm{~g}$ TTC dissolved in $100 \mathrm{~mL}$ distilled water) was prepared and stored in the dark at $4^{\circ} \mathrm{C}$ until used. Triphenyl formazan (TF) was used to establish a standard curve for absorbance $\left(\mathrm{OD}_{484}\right)$ vs TF concentration. Alcohols (ethanol and methanol) were used to extract TF from the cells. The Tris (hydroxymethyl-aminomethane), 2, 3, 5-triphenyl tetrazolium chloride (TTC) and 2, 3, 5-triphenyl formazan (TF) were obtained from Sigma-Aldrich (Oakville, Ontario, Canada) and the glucose was obtained from BioShop (Burlington, Ontario, Canada). Ethanol and methanol were obtained from Fisher Scientific (Montreal, Quebec, Canada).

\section{Media preparation}

Maltose-yeast extract-malt extract (MYM) agar and broth were used to cultivate Streptomyces venezuelae. The compositions of MYM agar and broth are shown in Table 1. All media components were obtained from BioShop (Burlington, Ontario, Canada). The media components were dissolved in distilled water then autoclaved (Sterile ax, Thermo Fisher Scientific, Ottawa, Ontario, Canada) on the liquid setting $\left(121^{\circ} \mathrm{C}\right.$ and $\left.20 \mathrm{~Pa}\right)$ for 15 minutes. The autoclaved agar was stored at $65^{\circ} \mathrm{C}$ to prevent solidification.

\section{Bacteria}

An initial starter plate of Streptomyces venezuelae ISP5230 was obtained from the Jakeman Laboratory, College of Pharmacy, Dalhousie University (Halifax, Nova Scotia, Canada) and stored at $4^{\circ} \mathrm{C}$. The surface growth was used to inoculate maltose-yeast extract-malt extract (MYM) agar plates or flasks with MYM broth as needed.
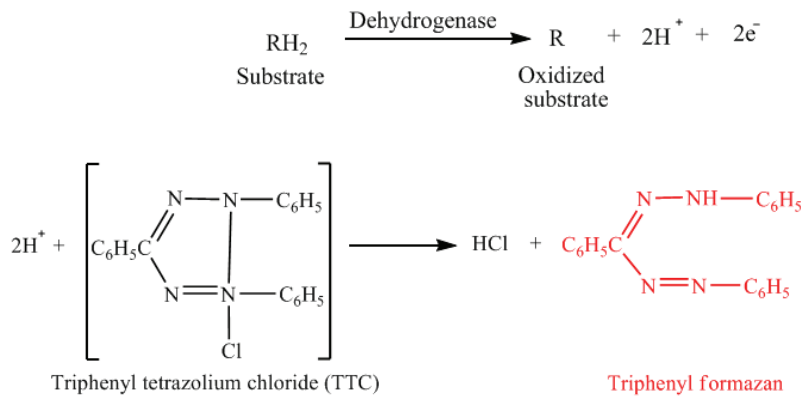

Figure 1: Mechanism showing the role of dehydrogenase in the reduction of triphenyl tetrazolium chloride (TTC) to triphenyl formazan (TF).

\begin{tabular}{|l|l|l|}
\hline \multirow{2}{*}{ Component } & Quantity (g/L distilled water) & \\
\cline { 2 - 3 } & Agar & Broth \\
\hline Maltose & 4.0 & 4.0 \\
\hline Yeast Extract & 4.0 & 4.0 \\
\hline Malt Extract & 10.0 & 10.0 \\
\hline MOPS & 1.9 & 1.9 \\
\hline Agar & 15.0 & - \\
\hline
\end{tabular}

Table 1: MYM media components.

\section{Experimental Procedure}

\section{Triphenyl formazan (tf) standard curve}

A standard curve was developed to determine the concentration of TF corresponding to an absorbance measurement at $484 \mathrm{~nm}$. A stock solution of $0.2 \mu \mathrm{mol} / \mathrm{mL}$ was prepared by dissolving $0.03 \mathrm{~g}$ TF in 500 $\mathrm{mL}$ methanol. The stock solution was diluted with methanol to produce 11 solutions with TF concentrations from $0.004 \mu \mathrm{mol} / \mathrm{mL}$ to $0.1 \mu \mathrm{mol} /$ $\mathrm{mL}$. The absorbance of each solution was measured using a spectrophotometer (Genesys 20, Thermo Scientific, Mississauga, Ontario, Canada) at a wavelength of $484 \mathrm{~nm}$. The absorbance readings were plotted against the TF concentration of the prepared solutions as shown in Figure 2. The following linear best-fit equation $\left(\mathrm{R}^{2}=0.98\right)$ was determined:

$$
A U_{484} \equiv 10.574 T F
$$

where:

$A U_{484}$ is the absorbance reading at $484 \mathrm{~nm}$

TF is the concentration of triphenyl formazan $(\mu \mathrm{mol} / \mathrm{mL}$ extraction solvent)

\section{Microbial growth}

Three $250 \mathrm{~mL}$ shake flasks were each filled with $175 \mathrm{~mL}$ of MYM broth, plugged with foam caps, covered with aluminum foil and autoclaved (SterileMax, Thermo Fisher Scientific, Ottawa, Ontario, Canada) at $121^{\circ} \mathrm{C}$ and $20 \mathrm{~Pa}$ for 15 minutes. The flasks were then inoculated with S. venezuelae and incubated in a controlled environment shaker (25 Incubator Shaker, New Brunswick Scientific, Edison, New Jersey, USA) at $30^{\circ} \mathrm{C}$ and $250 \mathrm{rpm}$. Each flask was sampled at $0,2,12,14,21,23,38,40$, 42, 60 and 64 hours after inoculation and the extent of cell growth was monitored over the period of 64 hour by measuring the optical density at $600 \mathrm{~nm}\left(\mathrm{OD}_{600}\right)$, the number of colony forming units (CFU) and the triphenyal formazan yield (TF).

\section{CFU determination}

A series of dilutions were carried out for the determination of the number of CFU. A $1 \mathrm{~mL}$ aliquot of the original sample was added to an autoclaved test tube containing $9 \mathrm{~mL}$ of autoclaved distilled water. The test tube was capped and inverted several times to distribute the

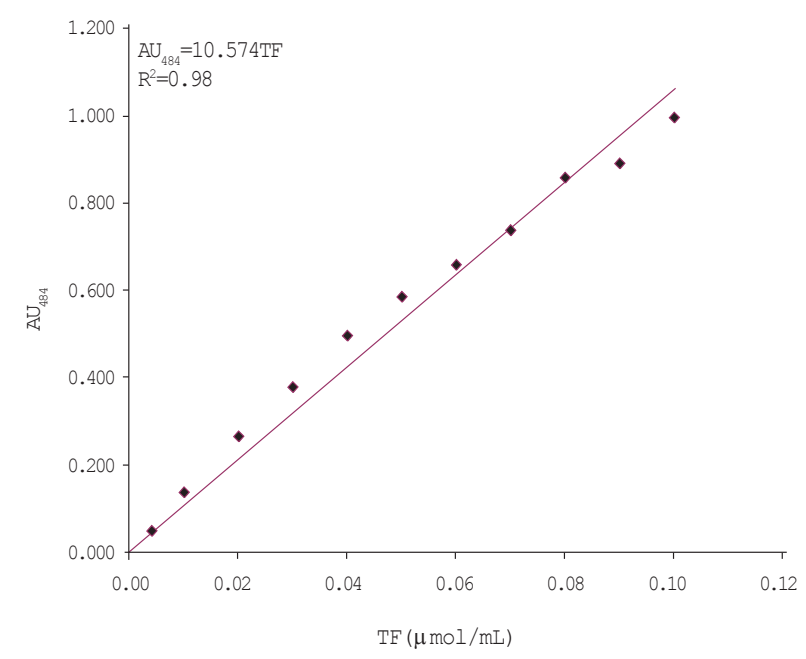

Figure 2: TF standard curve. 
cells. An aliquot of $1 \mathrm{~mL}$ of this solution was added to a second autoclaved test tube containing $9 \mathrm{ml}$ of autoclaved distilled water. This tube was capped and inverted to distribute the cells. This was carried out seven more times to a final dilution of $10^{-10}$. For each of the six dilutions used $\left(10^{-5}, 10^{-6}, 10^{-7}, 10^{-8}, 10^{-9}, 10^{-10}\right), 0.1 \mathrm{~mL}$ was added to a petri dish containing MYM agar in triplicate (given final plate dilutions of $10^{-6}$, $10^{-7}, 10^{-8}, 10^{-9}, 10^{-10}$, and $\left.10^{-11}\right)$. The plates were sealed with parafilm, inverted, and incubated at $30^{\circ} \mathrm{C}$ in an environmentally controlled incubator (model number 2020, VWR International, Cornelius, Oregon, USA) for 24 hours. Following the incubation period, the plates were removed and the colonies were counted. The plates that had between 30-300 CFU present were used for calculating the CFU of the samples.

\section{Dehydrogenase activity measurement}

$1 \mathrm{~mL}$ was pipetted from each sample into four test tubes. Tris buffer $(2.5 \mathrm{~mL})$ and TTC-glucose solution $(1 \mathrm{~mL})$ were added to the sample tubes ( $1 \mathrm{~mL}$ of distilled water was added to the control tube). The $\mathrm{pH}$ was adjusted to 7 using $1.0 \mathrm{~N} \mathrm{HCl}$ and the test tubes were gently swirled to mix the content. The tubes were incubated in an environmentally controlled incubator (model number 2020, VWR International, Cornelius, Oregon, USA) at $30^{\circ} \mathrm{C}$ for 1 hour. The tubes were removed and centrifuged (IEC CentraCL2, Thermo Electron Corporation, Mississauga, Ontario, Canada) for 10 minutes to separate the cells from other medium components. TF extraction was carried out three times using $2.5 \mathrm{~mL}$ of ethanol each time. All samples were vortexed (Thermolyne Maxi Mix, Thermolyne Corporation, Hampton, New Hampshire, USA) to disrupt cell walls and leach TF from within cells followed by centrifugation to separate the cells at the bottom. Supernatants from the three extractions were combined and the absorbance of the combined supernatants was measured at $484 \mathrm{~nm}$ (Genesys 20, Thermo Scientific, Mississauga, Ontario, Canada).

\section{Optimization experiments}

Experiments were conducted to determine the optimum test conditions that would reduce the most TTC to TF and extract the highest amount of TF from S. venezuelae during growth in MYM media. The dehydrogenase activity test parameters included: solvent type, number of solvent extractions, incubation time, incubation temperature and medium $\mathrm{pH}$. The values for each parameter are shown in Table 2. The study was carried out in two phases as shown in Figure 3. First, initial experiments were conducted to determine the optimal number of solvent extractions and best solvent type. Then, the best solvents and optimum number of extraction obtained from the initial experiments were used in further experiments to determine the best time, temperature and $\mathrm{pH}$.

\section{Number of extractions}

To evaluate the effect of the number of extractions on the TF yield from each flask, samples were taken from the growing culture at 21, 37, 47, 62 and 64 hours after inoculation. At each sampling time, $1 \mathrm{~mL}$ aliquots were transferred into four test tubes (tests were carried out

\begin{tabular}{|l|l|l|l|l|}
\hline $\begin{array}{c}\text { Extraction } \\
\text { Solvent }\end{array}$ & $\begin{array}{c}\text { Number of } \\
\text { Extractions }\end{array}$ & $\begin{array}{c}\text { Incubation } \\
\text { Time (hour) }\end{array}$ & $\begin{array}{c}\text { Incubation Tem- } \\
\text { perature }\left({ }^{\circ} \mathbf{C}\right)\end{array}$ & Medium pH \\
\hline Methanol & 1 & 1 & 22 & 6 \\
\hline Ethanol & 2 & 2 & 30 & 7.5 \\
\hline & 3 & 3 & 40 & 9 \\
\hline & & 4 & 50 & \\
\hline
\end{tabular}

Table 2: Dehydrogenase activity assay conditions.

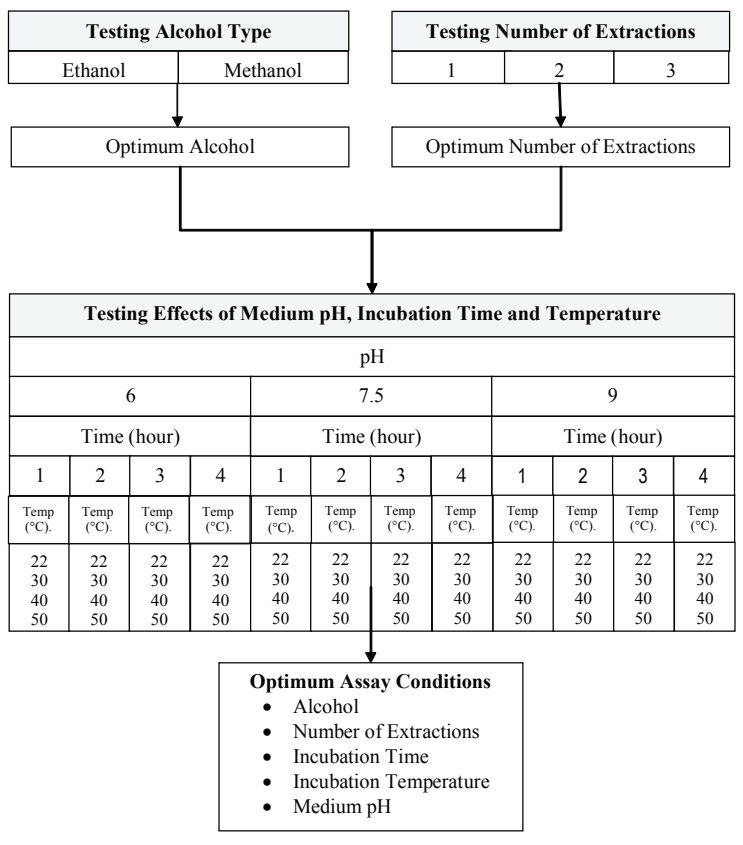

Figure 3: Experimental Design

in triplicates with a control for each sample). Tris buffer $(2.5 \mathrm{~mL})$ was added to all test tubes. Then, $1 \mathrm{~mL}$ of TTC/glucose solution was added to each of the sample test tubes $(1 \mathrm{ml}$ of distilled water to control test tubes). The $\mathrm{pH}$ was adjusted to 6 using $1 \mathrm{~N} \mathrm{HCl}$. The test tubes were gently swirled to mix the contents, incubated in a controlled temperature oven at $50^{\circ} \mathrm{C}$ (Isotemp Oven, model $630 \mathrm{~F}$, Fisher Scientific, Ottawa, Ontario, Canada) for 1 hour. Samples were then centrifuged (IEC CentraCL2, Thermo Electron Corporation, Mississauga, Ontario) for 10 minutes to separate the cells from the liquid media. The supernatant was discarded and $2.5 \mathrm{~mL}$ of ethanol was added to the cells. All samples were vortexed (Thermolyne Maxi Mix, Thermolyne Corporation, Hampton, New Hampshire, USA) to aid in the extraction of TF (red colour) from the cells. Samples were centrifuged again, the supernatant decanted and absorbance measured at $484 \mathrm{~nm}$ using the control to zero the spectrophotometer (Genesys 20, Thermo Scientific, Mississauga, Ontario, Canada). A second extraction with ethanol was carried out, the supernatant was combined with that from the first extraction and the absorbance was measured. A third extraction with ethanol was carried out, the supernatant combined with those from the previous two extractions and the absorbance was measured.

\section{Type of extraction solvent}

To evaluate the effectiveness of solvent in extracting TF, samples were taken from the growing culture at 21, 37, 47, 62 and 64 hours. At each sampling time, aliquots $(1 \mathrm{~mL})$ were transferred from each flask into the two groups of test tubes (ethanol and methanol). Tests were carried out in triplicates and a control for each flask sampled and solvent tested. Tris buffer $(2.5 \mathrm{~mL})$ was added to all the test tubes and 1 $\mathrm{mL}$ of the TTC/glucose solution was added to the sample test tubes (or $1 \mathrm{~mL}$ of distilled water to control test tubes). The $\mathrm{pH}$ was adjusted to 6 using $1 \mathrm{~N} \mathrm{HCl}$. The test tubes were gently swirled to mix the contents and incubated at $50^{\circ} \mathrm{C}$ for 1 hour in a temperature controlled oven (Isotemp Oven, model 630F, Fisher Scientific, Ottawa, Ontario, Canada). Samples were then centrifuged (IEC CentraCL2, Thermo Electron Cor- 
poration, Mississauga, Ontario) for 10 minutes and the supernatant discarded. Extraction of TF was carried out three times using $2.5 \mathrm{~mL}$ of either methanol or ethanol. After each addition of solvent to the cells, the samples were vortexed, centrifuged and the supernatant decanted. The absorbance of the supernatants collected from three extractions for each solvent for each solvent was measured at $484 \mathrm{~nm}$ using a spectrophotometer (Genesys 20, Thermo Scientific, Mississauga, Ontario, Canada).

\section{Incubation time, temperature and medium ph}

After 64 hours of growth, the contents of all flasks were combined into a $1 \mathrm{~L}$ flask and refrigerated at $4^{\circ} \mathrm{C}$ until required. For each incubation temperature investigated $\left(22^{\circ} \mathrm{C}, 30^{\circ} \mathrm{C}, 40^{\circ} \mathrm{C}\right.$ and $\left.50^{\circ} \mathrm{C}\right)$, three medium $\mathrm{pH}$ values $(6,7.5$ and 9) and four incubation times (1, 2, 3 and 4 hours) were tested. The resulting 48 tests were carried out in triplicate with a control. For all tests, $1 \mathrm{~mL}$ aliquots of the MYM broth with $S$. venezuelae growth were added to test tubes. The $\mathrm{pH}$ was adjusted to $6,7.5$ or 9 using $1 \mathrm{~N} \mathrm{HCl}$ or $\mathrm{NaOH}$ as needed. Tris buffer $(2.5 \mathrm{~mL})$ and TTC/glucose solution $(1 \mathrm{~mL})$ were added to each tube. Tubes were manually swirled to mix contents and incubated for either $1,2,3$, or 4 hours. Tubes were incubated at $22^{\circ} \mathrm{C}$ or $30^{\circ} \mathrm{C}$ in controlled environment incubator (Model 2020, VWR International, Cornelius, Oregon, USA), and at $40^{\circ} \mathrm{C}$ or $50^{\circ} \mathrm{C}$ in temperature controlled oven (Isotemp Oven, model 630F, Fisher Scientific, Ottawa, Ontario, Canada). Samples were then centrifuged (IEC CentraCL2, Thermo Electron Corporation, Mississauga, Ontario) for 10 minutes and the supernatant discarded. Extraction of TF was carried out three times using $2.5 \mathrm{~mL}$ methanol each time. After each addition of solvent to the cells, the samples were vortexed, centrifuged and the supernatant decanted. The supernatants obtained from the three extractions were combined after each extraction and the absorbance was measured at $484 \mathrm{~nm}$ using a spectrophotometer (Genesys 20, Thermo Scientific, Mississauga, Ontario, Canada).

\section{Results}

\section{Microbial growth}

The microbial growth as determined by measuring optical density at $600 \mathrm{~nm}\left(\mathrm{OD}_{600}\right)$, the number of colony forming units (CFU) and the triphenyl fromazan (TF) yield. The results are presented in Figure 4. There was an initial lag period followed by exponential growth phase. The lag period and specific growth phase were determined graphically according to the procedure described by [15] as shown in Figure 5. The lag period and specific growth were 10.3 hour and $0.3 \mathrm{~h}^{-1}$, respectively.

\section{Number of extractions}

In order to test the effect of the number of extractions on the final TF yield from S. venezualae cells grown in MYM broth, one, two and three extractions were carried out at a medium $\mathrm{pH}$ of 6 , an incubation time of 1 hour and an incubation temperature of $50^{\circ} \mathrm{C}$. The results presented in Figure 6 showed higher TF yields with increasing number of extractions at all sampling times (different population sizes). The results also showed that the stationary growth phase was reached after the 60 hours of growth.

\section{Type of extraction solvent}

Ethanol and methanol were used to extract TF from samples taken during the growth of $S$. venezuelae cells. The test was carried out using three extractions at a medium $\mathrm{pH}$ of 6 , an incubation temperature of $50^{\circ} \mathrm{C}$ and an incubation time of 1 hour. The TF results shown in Figure

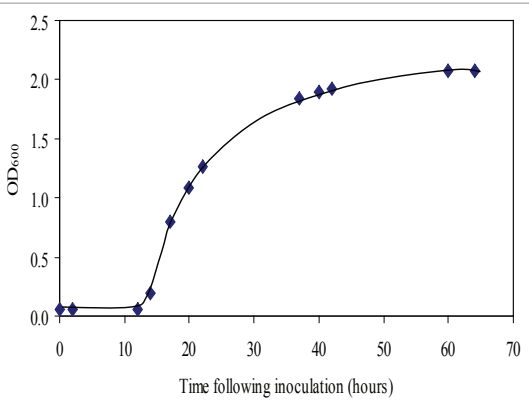

(a) Optical density

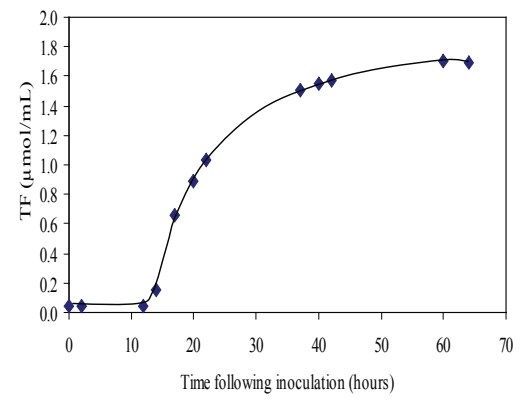

(b) TF yield

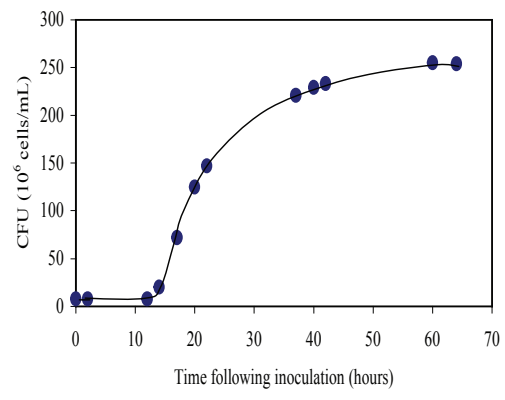

(c) $\mathrm{CFU}$

Figure 4: S. venezuelae growth measured by optical density, TF yield and CFU.

7 indicated that both solvents showed an increase in TF yield over the time as the number of bacteria increased. The results also showed that the TF extracted by ethanol and methanol started to decline after 60 hours of growth indicating the start of the stationary growth phase.

\section{Medium pH}

Figures 8 and 9 show the effect of $\mathrm{pH}$ on TF yield at varying incubation temperatures and incubation times, respectively. All plots display a similar concave shape with the $\mathrm{pH}$ value of 7.5 resulting in the lowest TF yield and the $\mathrm{pH}$ of 6 resulting in the greatest TF yield at all incubation times and temperatures. However, longer incubation time and lower temperature resulted in slightly higher TF yields.

\section{Incubation time}

Figures 10 and 11 show the effect of incubation time on TF yield 
Citation: Burdock TJ, Brooks MS, Ghaly AE (2011) A Dehydrogenase Activity Test for Monitoring the Growth of Streptomyces Venezuelae in a Nutrient Rich Medium. J Bioprocess Biotechniq 1:101 doi:10.4172/2155-9821.1000101

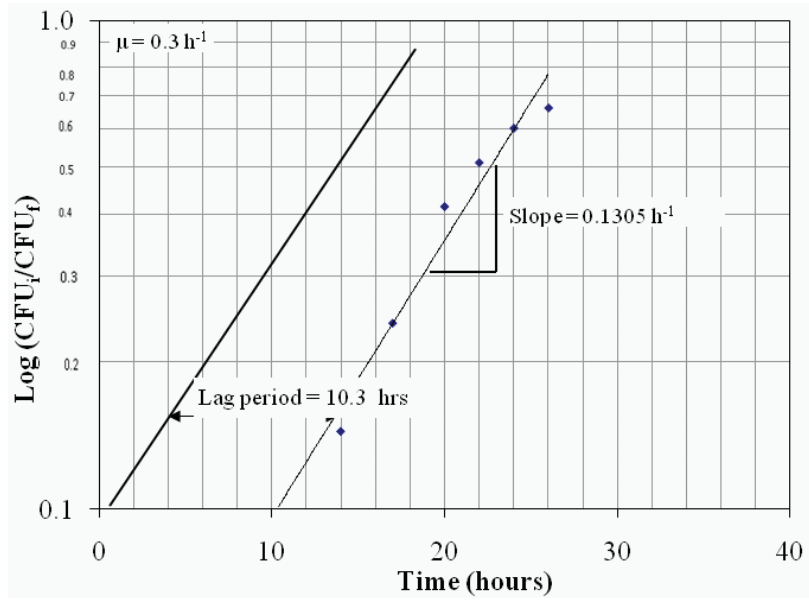

Figure 5: Graphical determination of the lag period and specific growth rate.

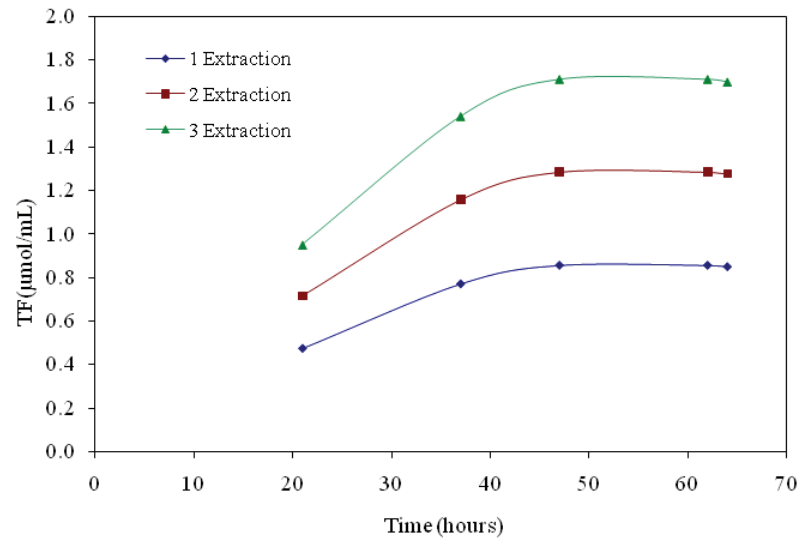

Figure 6: Effect of number of extractions using ethanol on TF yield from $S$. venezuelae (incubation time $=1$ hour; incubation temperature $=50^{\circ} \mathrm{C}$; $\mathrm{pH}=6)$.

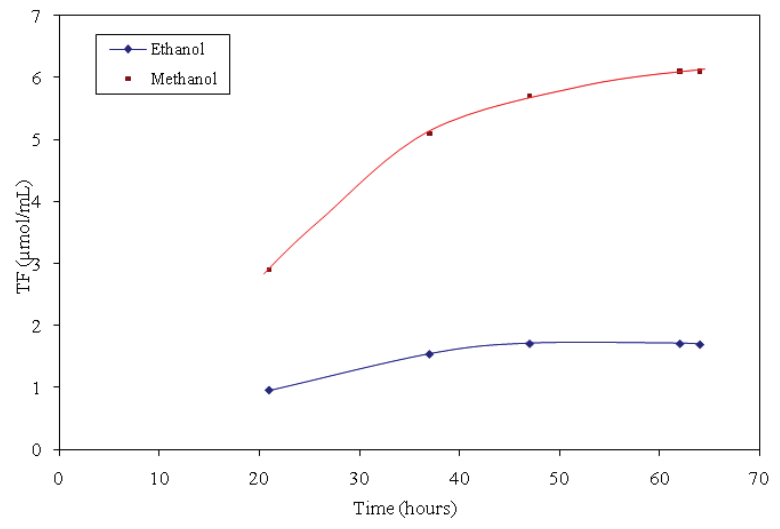

Figure 7: Effect of alcohol type on TF yield from S. venezuelae (incubation time $=1$ hour; incubation temperature $=50^{\circ} \mathrm{C} ; \mathrm{pH}=6$; number of extraction $=3$ ).
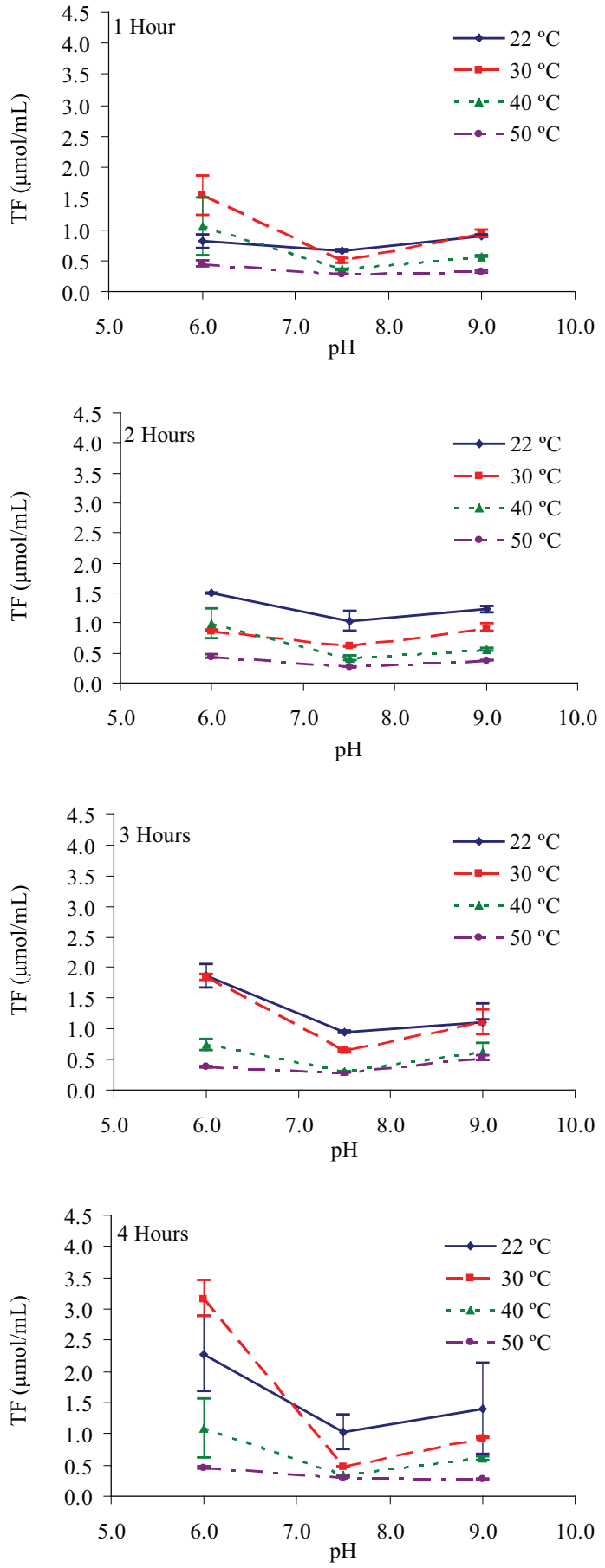

Figure 8: Effect of $\mathrm{pH}$ on TF yield at various incubation temperatures.

at different medium $\mathrm{pH}$ values and incubation temperatures, respectively. At all incubation times, higher incubation temperatures $\left(40^{\circ} \mathrm{C}\right.$ and $50^{\circ} \mathrm{C}$ ) resulted in lower TF yields than those obtained at the lower temperatures $\left(22^{\circ} \mathrm{C}\right.$ and $\left.30^{\circ} \mathrm{C}\right)$ but the highest TF yields were always achieved at a $\mathrm{pH}$ of 6 . It seems that the effect of incubation time was dependent on the temperature. At higher temperatures $\left(40^{\circ} \mathrm{C}\right.$ and $\left.50^{\circ} \mathrm{C}\right)$, 1 hour incubation time produced the higher TF yield while at lower temperature $\left(22^{\circ} \mathrm{C}\right.$ and $\left.30^{\circ} \mathrm{C}\right), 4$ hours incubation time produced the highest TF yield. 

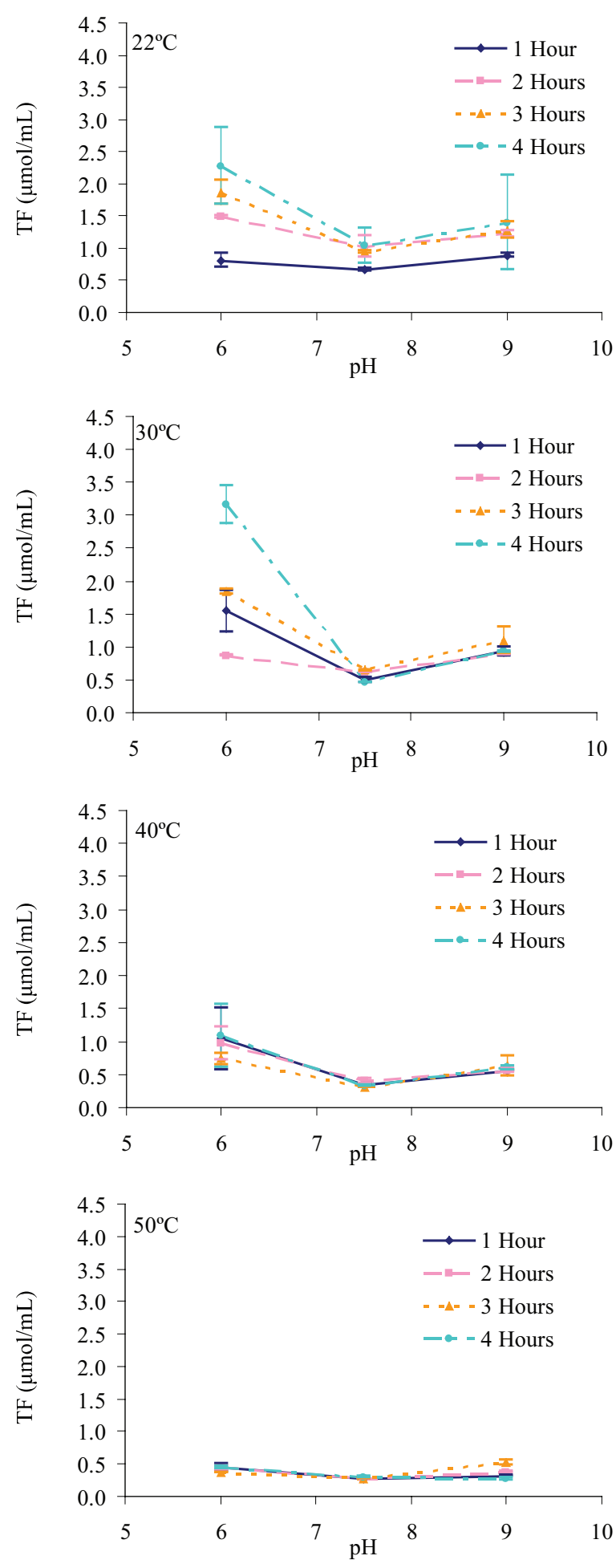

Figure 9: Effect of $\mathrm{pH}$ on TF yield at various incubation times.

\section{Incubation temperature}

Figures 12 and 13 show the effect of incubation temperature on $\mathrm{TF}$ yield at different $\mathrm{pH}$ values and incubation times, respectively. For all incubation temperatures, the highest TF yield was obtained at a $\mathrm{pH}$ of 6. However, the incubation temperatures of $22^{\circ} \mathrm{C}$ and $30^{\circ} \mathrm{C}$ appeared
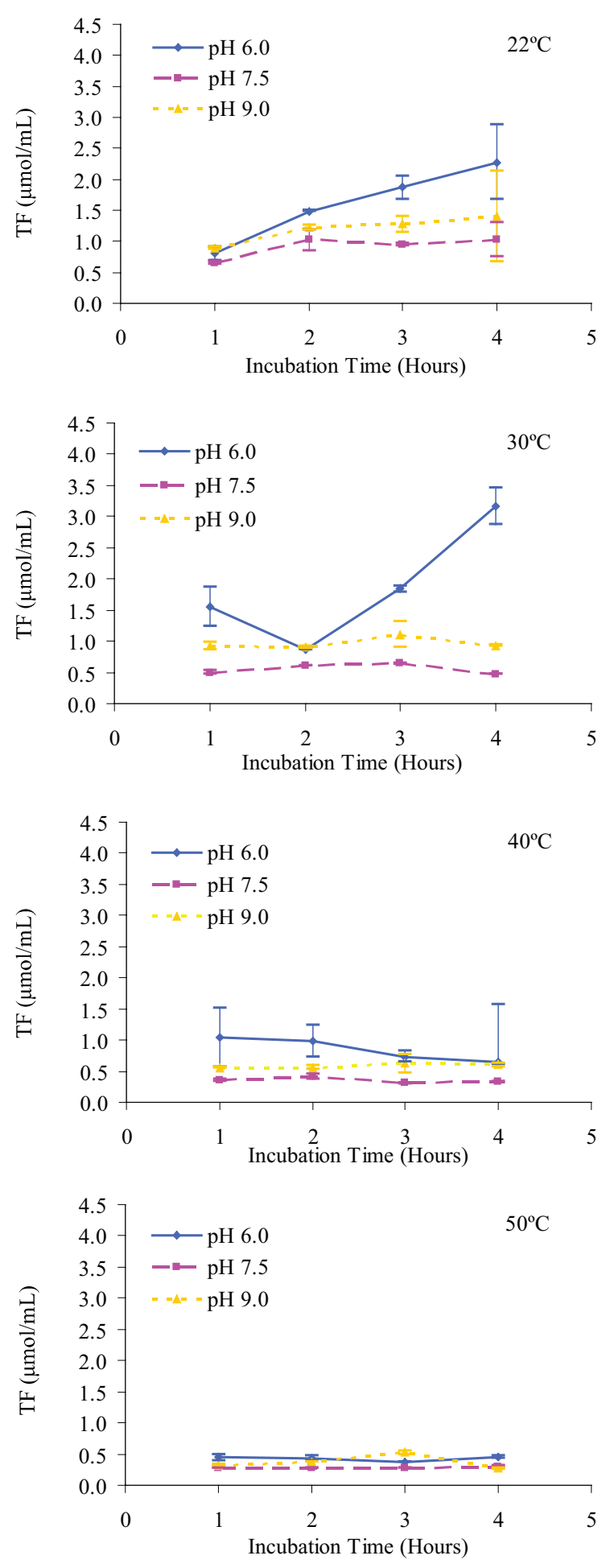

Figure 10: Effect of incubation time on TF yield at various pHs.

to result in higher TF yields than those observed at higher incubation temperatures $\left(40^{\circ} \mathrm{C}\right.$ and $\left.50^{\circ} \mathrm{C}\right)$.

\section{Discussion}

Jakeman et al. (2006) monitored S. venezuelae population during 

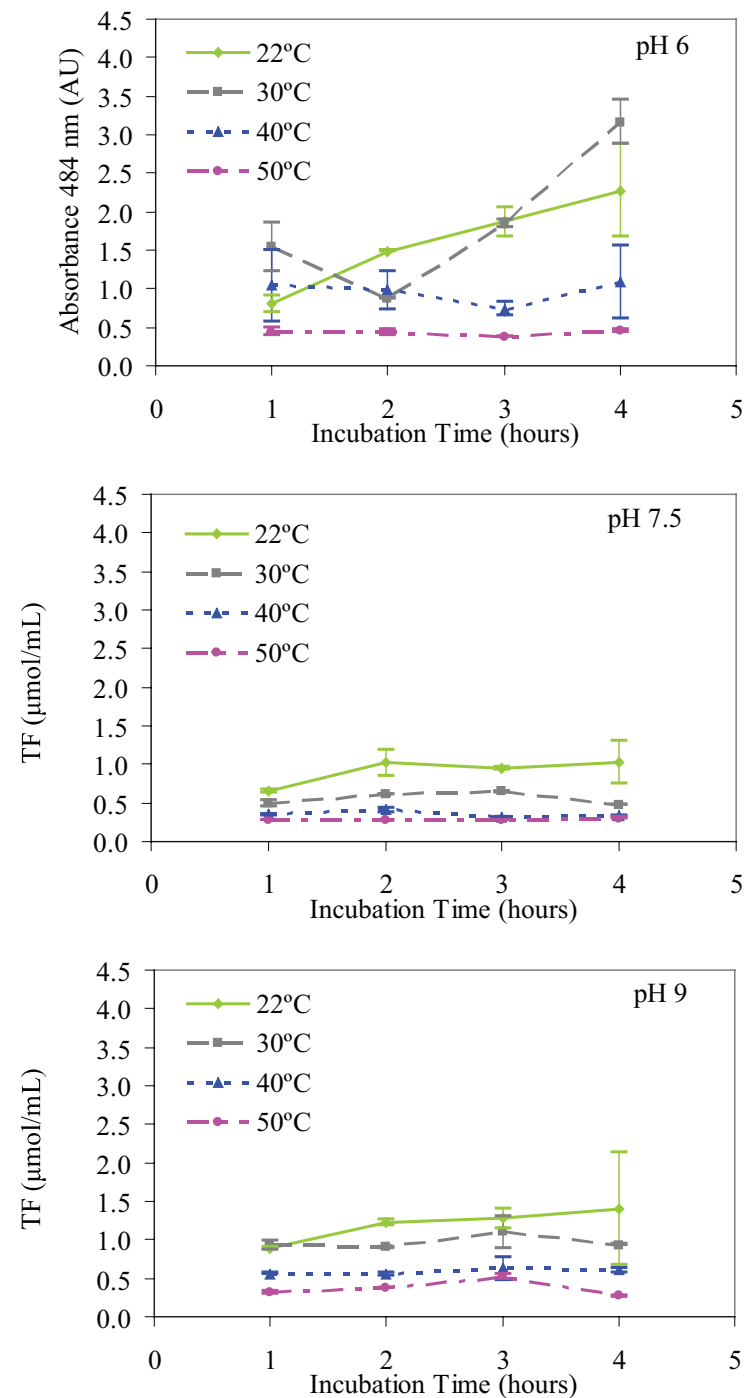

Figure 11: Effect of incubation time on TF yield at various incubation temperatures.

the growth period by measuring the optical density at $600 \mathrm{~nm}\left(\mathrm{OD}_{600}\right)$. In this study, the change of $S$. venezuelae population during the growth period was monitored by measuring the optical density at $600 \mathrm{~nm}$ $\left(\mathrm{OD}_{600}\right)$, the number of colony forming units (CFU) and the triphenyl formazan yield (TF). The relationships between $\mathrm{CFU}, \mathrm{OD}_{600}$ and $\mathrm{TF}$ are presented in Figure 14. The amount of TF extracted had a much better correlation with $\mathrm{CFU}$ than that observed between the $\mathrm{CFU}$ and $\mathrm{OD}_{600}$. The results clearly indicated the effectiveness of dehydrogenase activity as an accurate measure of cell growth.

The $\mathrm{OD}_{600}$, TF yield and CFU curves showed a lag period of approximately 10.3 hours, during which $S$. venezuelae adjusted to the new growth medium and environmental conditions. After the initial lag period, the bacteria grew exponentially before reaching the stationary phase at approximately 60 hours. The specific growth measured in this study was $0.3 \mathrm{~h}^{-1}$. [21] reported maximum specific growth rate of 0.23 $\mathrm{h}^{-1}$ for $S$. venezuelae grown in media containing soluble starch at $30^{\circ} \mathrm{C}$. [22] reported a maximum specific growth rate of $0.14 \mathrm{~h}^{-1}$ for $S$. venezuelae grown in MYM medium at $27^{\circ} \mathrm{C}$.
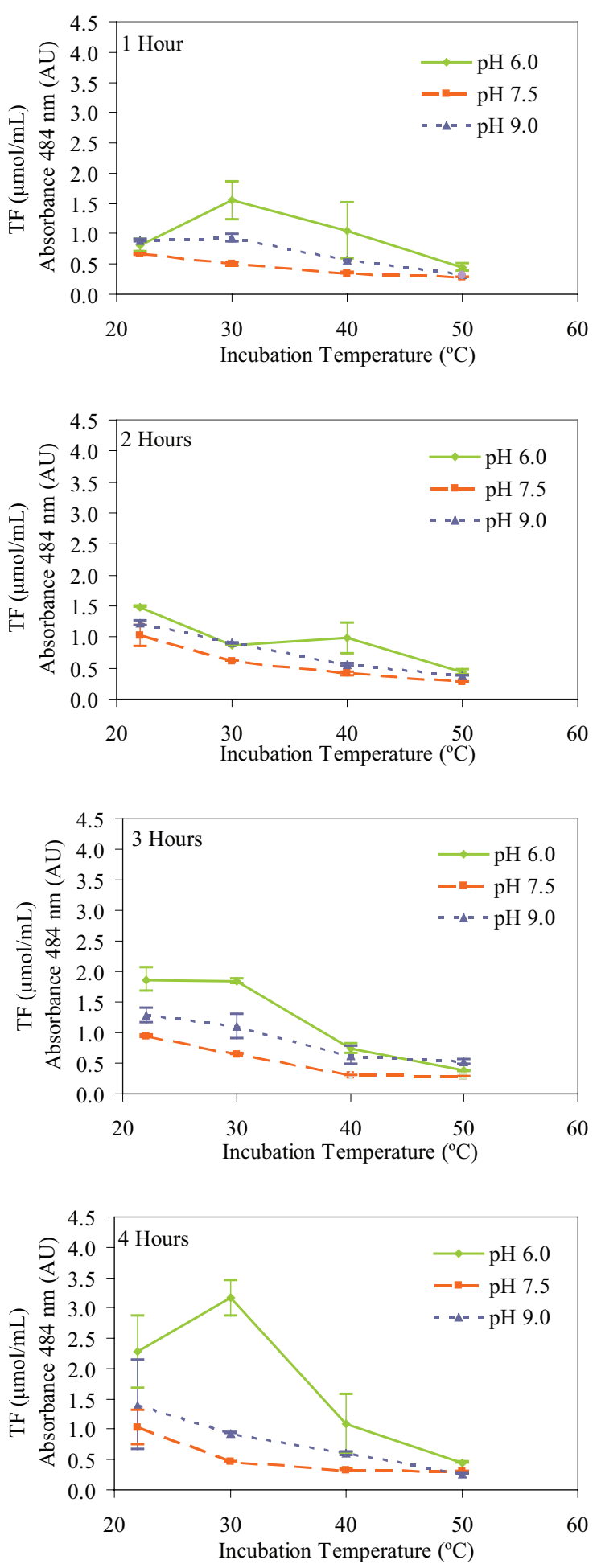

Figure 12: Effect of incubation temperature on TF yield at various $\mathrm{pHs}$.

The specific TF yield ( $\mu \mathrm{mol} / \mathrm{CFU}$ ) was calculated by dividing the TF yield by the CFU in order to assess the cell activity during the growth period. Figure 15 indicated that the cell activities during the lag phase $\left(0.65 \times 10^{-8} \mu \mathrm{mol} / \mathrm{CFU}\right)$ and stationary phase $\left(0.67 \times 10^{-8} \mu \mathrm{mol} / \mathrm{CFU}\right)$ were lower than that observed during the exponential growth period 

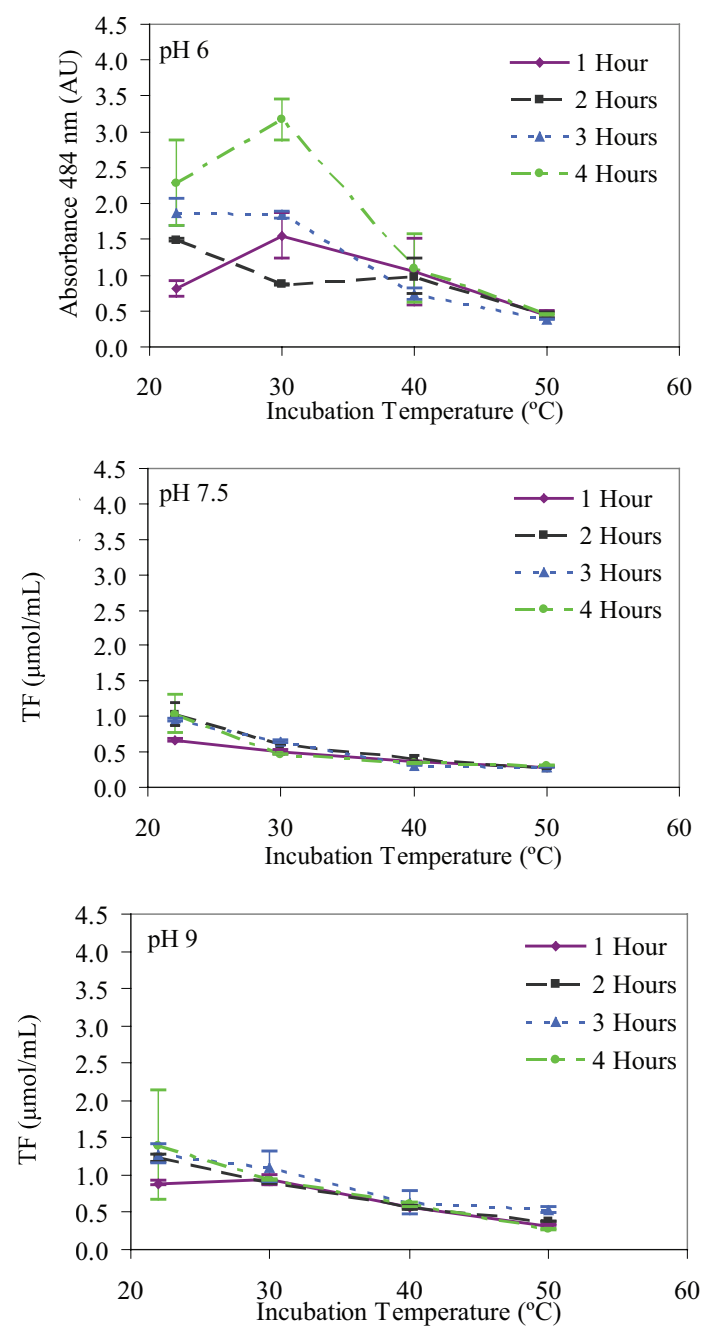

Figure 13: Effect of incubation temperature on TF yield at different incubation times.

$\left(0.7 \times 10^{-8} \mu \mathrm{mol} / \mathrm{CFU}\right)$. However, the specific TF yield remained constant during the entire growth period indicating the accuracy of TF as a measure of the cell growth.

\section{Number of extractions}

It was observed that for most cases, all of the red colour was removed from the pelletized cells after three extractions. Thus, the dehydrogenase activity test for $S$. venezuelae using TTC should be carried out with at least three extractions in order to achieve the highest TF yield. Other researchers observed a higher recovery of formazan using sequential extractions [17, 23-25]. Green and Nahara (1980) found that extraction with ethanol followed by ethyl acetate achieved the highest yield from muscle cells, but lower yields were observed when the solvents were reversed. They also observed lower TF yields when one and two extractions were done with the same solvent and concluded that the number of extractions was a critical factor that must be considered when developing tests involving solubilization of formazan. In the study by Ghaly and Mahmoud (2006), two extractions with ethanol were found sufficient to extract TF from Aspergillus niger vegetative cells. This indicates that the number of extractions may depend on the type of cells.
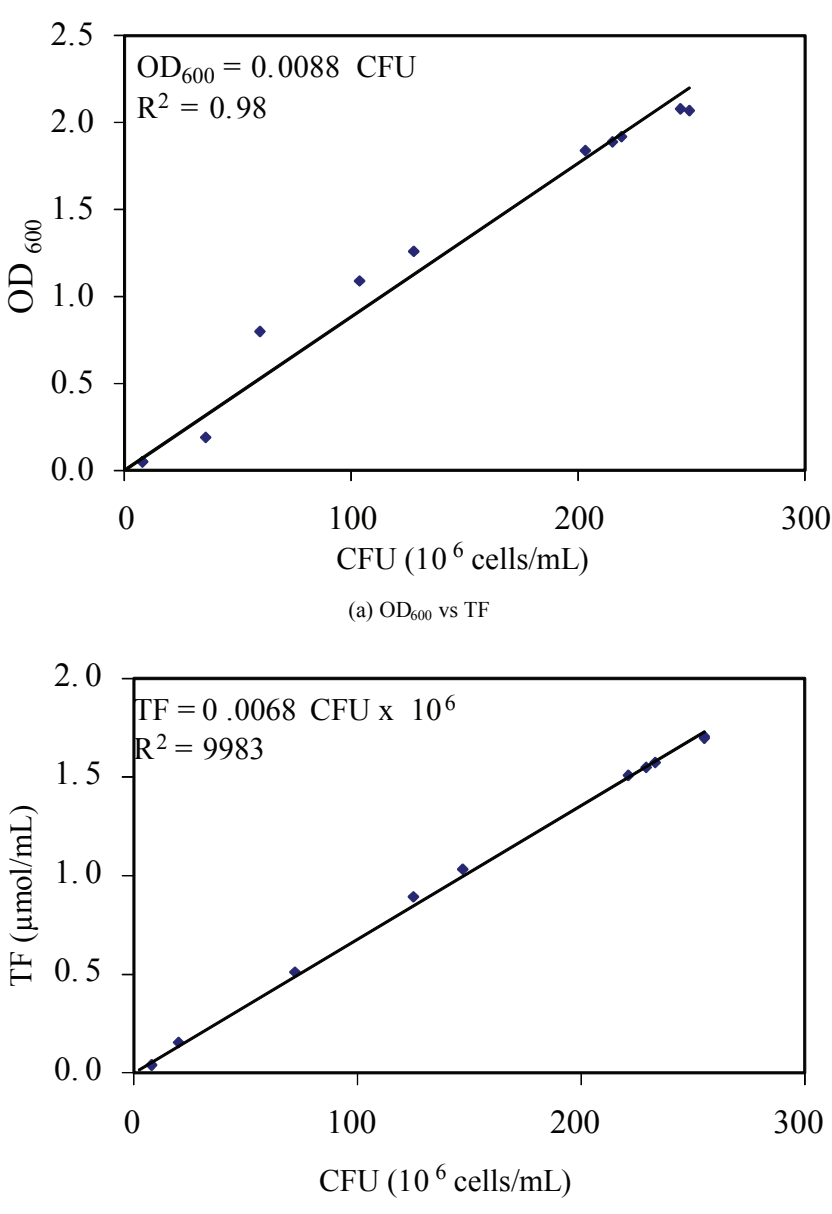

(b) CFU vs TF

Figure 14: The relationships between CFU, OD600 and TF.

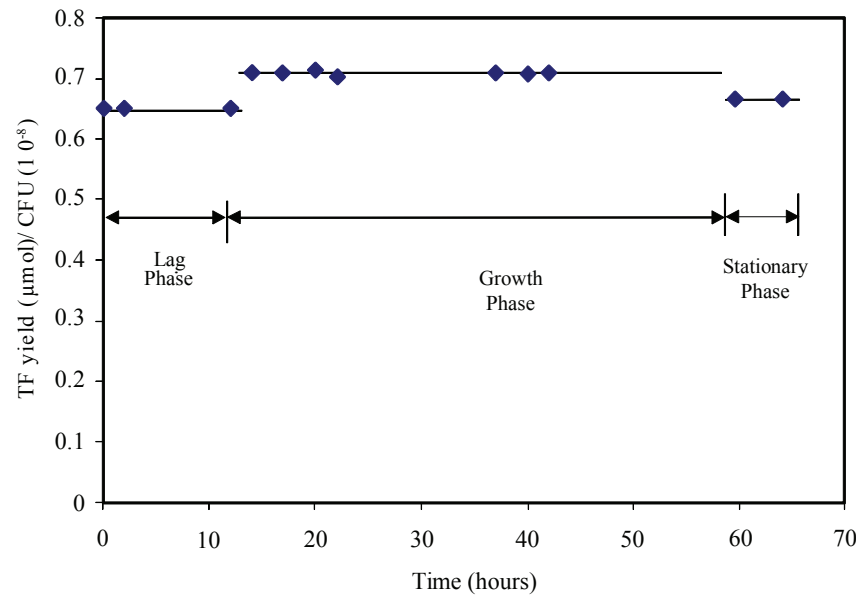

Figure 15: The activity of $S$. venezuelae as measured by specific TF yield during growth in MYM broth.

The specific TF yield ( $\mu \mathrm{mol} / \mathrm{CFU}$ ) of the three extractions from the samples taken at 21,37, 47, 62 and 64 hours was calculated Table 3 . The results indicated that $2^{\text {nd }}$ and $3^{\text {rd }}$ extractions increased the TF yield by 
$51 \%$ and $100 \%$ respectively. Also, the cell activity remained constant during the exponential growth period (at the 21, 37 and 47 hours) and slightly decreased during the stationary growth period (after 62 and 64 hours).

\section{Type of solvent}

It was noticed that after three washes with ethanol, the cell pellets were still red, which may explain why the TF yield from ethanol was lower. Thus, methanol is the better solvent to use for measuring dehydrogenase activity in S. venezuelae using TTC. In the study by Burton and Lanza (1986), the dehydrogenase activities of microbial consortia from sediment slurry samples were measured with TTC using different solvents. They ranked the solvents based on TF yield from highest to lowest as follows: tetrachloroethylene, acetone, propanol, ethanol and methanol. However, the differences between ethanol and methanol were not statistically significant at the 95\% confidence level. Tayler and May (2000) [26] found that for the tetrazolium salt INT (2-(4-iodophenyl)-3-(4nitrophenyl)-5-phenyl tetrazolium chloride), methanol was found to be a better solvent than $95 \%$ ethanol for the extraction of INT-formazan from bacterial cells. Lee et al. (1988) [27] investigated the extraction of INT-formazan in activated sludge and filamentous bacteria and found methanol to be less effective than dimethylsulfoxide (DMSO) and tetrachloroethylene/acetone as solvents. However, by increasing the permeability of the cells with lysozyme or Triton X-100 prior to using methanol, the same level of formazan yield was achieved as with the other solvents. This indicates that the ability of the solvent to permeate the cells is a critical factor in the extraction of formazan. In the present study, methanol was better able to permeate the cells than ethanol.

The specific TF yield ( $\mu \mathrm{mol} / \mathrm{CFU}$ ) after three extractions with ethanol and methanol at 21,37, 47, 62 and 64 hours was calculated Table 4. The results showed that the TF yield for methanol was $259 \%$ higher than that of ethanol. Also, the specific TF yield remained constant during the exponential growth period (at the 21, 37 and 47 hours) and slightly decreased during the stationary growth periods (at the 62 and 64 hours).

\section{Medium pH}

Several researchers reported high TF yields at different $\mathrm{pH}$ values. For example, Mahmoud and Ghaly (2004) found that at $\mathrm{pH}$ less than 7 , no reduction of TTC occurred for both cheese whey (Kluyveromyces fragilis) and compost materials (mixed culture). Ghaly and Ben-Hassan (1993) [28] found that maximum dehydrogenase activities for both Kluyveromyces fragilis and Candida pseudotropicalis yeasts grown in cheese whey were at a $\mathrm{pH}$ of 7 and the activities were reduced at the acidic and basic levels of pH. Backor and Fahselt (2005) [29] reported that significantly acidic pHs (1.5 - 3) resulted in lower TTC reduction in lichens. Ghaly and Mahmoud (2006) [30] observed higher TF yield at a $\mathrm{pH}$ of 9 for $A$. niger grown in chitin. However, Mahmoud and Ghaly (2004) reported non-enzymatic reduction of TTC to TF at high $\mathrm{pH}$ values. In this study, a $\mathrm{pH}$ of 6 was the most appropriate value for measuring dehydrogenase activity in S. venezuelae during growth in MYM broth. It is not clear however if non-enzymatic reduction of TTC to TF occurred at $\mathrm{pH} 9$.

\section{Incubation time}

The results showed slight increase in TF yield as when the incubation time increased from 1 hour to 4 hours. Several investigators reported that incubating samples for longer times increased the extent of TTC reduction to TF. Mahmoud and Ghaly (2006) reported that TF yield

\begin{tabular}{|c|c|c|c|}
\hline \multirow{2}{*}{$\begin{array}{c}\text { Time } \\
\text { (hours) }\end{array}$} & \multicolumn{3}{|c|}{ Specific TF Yield $\left(10^{-8} \mu \mathrm{mol} / \mathrm{CFU}\right)$} \\
\hline & $1^{\text {st }}$ Extraction & $2^{\text {nd }}$ Extraction & $3^{\text {rd }}$ Extraction \\
\hline 21 & 0.35 & 0.53 & 0.70 \\
\hline 37 & 0.35 & 0.52 & 0.70 \\
\hline 47 & 0.35 & 0.53 & 0.70 \\
\hline 62 & 0.33 & 0.50 & 0.67 \\
\hline 64 & 0.33 & 0.50 & 0.67 \\
\hline
\end{tabular}

Table 3: Specific TF yield for various ethanol extractions at various sampling time

\begin{tabular}{|c|c|c|}
\hline \multirow{2}{*}{$\begin{array}{c}\text { Time } \\
\text { (hours) }\end{array}$} & Specific TF Yield (10-8 $\mu \mathrm{mol} / \mathrm{CFU})$ & \\
\hline & Ethanol & Methanol \\
\hline 21 & 0.70 & 2.51 \\
\hline 37 & 0.70 & 2.51 \\
\hline 47 & 0.70 & 2.51 \\
\hline 62 & 0.67 & 2.49 \\
\hline 64 & 0.67 & 2.49 \\
\hline
\end{tabular}

Table 4: Specific TF yield for ethanol and methanol at various sampling time.

for A. niger grown in chitin increased exponentially when incubation time was increased form 1.5 hours to 4.5 hours. Ghaly and Ben-Hassan (1993) reported increased TF yield with increased incubation time for both Kluyveromyces fragilis and Candida pseudotropicalis yeasts grown in cheese whey, but the TF yield started to plateau after 80 hours in both cases. Mathew and Obbard (2001) [31] reported increased INT-formazan yield with increased incubation time for petroleum-contaminated beach sediments, but the TF yield started to level off after 22 hours of incubation. Although the TF yield obtained at an incubation period of 4 hours was slightly higher than the TF yield obtained at an incubation time of 1 hour, it is more practical to use 1 hour since the resulting TF yield is measurable and can provide good representation of cell growth and activity.

\section{Incubation temperature}

In the literature, there have been reports of higher TF yields as a result of increasing incubation temperature for microbial populations $[30,32]$. In this study, higher temperature $\left(40^{\circ} \mathrm{C}\right.$ and $\left.50^{\circ} \mathrm{C}\right)$ showed a negative effect on the activity of the bacteria probably due to enzymatic inhibition at higher temperature [34]. According to Breed (1957) [33] S. venezuelae are soil bacteria, and therefore, achieve optimal growth with the lower temperature ranges investigated $\left(22^{\circ} \mathrm{C}-30^{\circ} \mathrm{C}\right)$ in this study. Doull et al. (1993) reported a decreased growth for $S$. venezuelae at temperatures of $37^{\circ} \mathrm{C}$ and $42^{\circ} \mathrm{C}$, compared to that at a control temperature of $27^{\circ} \mathrm{C}$. Therefore, $30^{\circ} \mathrm{C}$ is an optimum temperature for measuring the dehydrogenase activity of $S$. venezuelae with TTC test.

\section{Conclusions}

A dehydrogenase activity measurement test using triphenyl tetrazolium chloride (TTC) was successfully developed for Streptomyces venezuelae growth in MYM broth. TF yield $(\mu \mathrm{mol} / \mathrm{mL})$ was related to the number of cells was measured by optical density $\left(\mathrm{OD}_{600}\right)$. It was found that methanol was able to extract a greater yield of the red triphenyl formazan (TF) than ethanol and that the TF yield increased with the number of extractions. High TF yields were observed at low $\mathrm{pH}$ value and/or low temperatures. Lower temperatures $\left(22-30^{\circ} \mathrm{C}\right)$ required longer incubation time compared to higher temperature $\left(40-50^{\circ} \mathrm{C}\right)$. Based on the results obtained from this study, the optimum conditions for measuring the dehydrogenase activity of $S$. venezuelae (reducing TTC to $\mathrm{TF}$ and extracting highest amount of TF) are three extractions with 
Citation: Burdock TJ, Brooks MS, Ghaly AE (2011) A Dehydrogenase Activity Test for Monitoring the Growth of Streptomyces Venezuelae in a Nutrient Rich Medium. J Bioprocess Biotechniq 1:101 doi:10.4172/2155-9821.1000101

Page 10 of 10

methanol after incubation time of 1 hour at a medium $\mathrm{pH}$ of 6 and incubation temperature of $30^{\circ} \mathrm{C}$.

\section{Acknowledgements}

The research was funded by the National Science and Engineering Research Council (NSERC) of Canada.

\section{References}

1. Zheng J, Rix U, Mattingly C, Adams V, Chen Q, et al. (2005) Cytotoxic activities of new jadomycin derivatives. J. Antibi 58: 405-408.

2. Doull JL, Singh AK, Hoare M, Ayer SW (1994) Conditions for the production of jadomycin B by Streptomyces venezuelae ISP5230: effects of heat shock, ethanol treatment and phage infection. J. Ind Microbio 13: 120-125.

3. Jakeman DL, Farrell S, Young W, Doucet RJ, Timmons SC (2005) Novel jadomycins: incorporation of non-natural and natural amino acids. Bioorg Med Chem Lett 15: 1447-1449.

4. Burdock TJ, Giffin AH, Brooks MS, Ghaly AE (2008) Heat Balance analysis during the production of jadomycin C. Amer J Biochem Biotech 4: 7-18.

5. Jakeman DL, Graham CL, Young W, Vining LC (2006) Culture conditions improving the production of jadomycin B. J Ind Microbio Biotech 33: 767-772

6. Balestra GM and Misaghi IJ (1997) Increasing the efficiency of the plate counting method for estimating bacterial diversity. J. Microbio Method 30: 111-117.

7. Lindqvist R (2006) Estimation of staphylococcus aureus growth parameters from turbidity data: characterization of strain variation and comparison of methods. Applied and Environmental Microbiology 72: 4862-4870.

8. Lebaron P, Troussellier M, Got P (1994) Accucary of epifluorescence microscopy counts for direct estimates of bacterial numbers. J. Microbio Method 19 89-94.

9. Beyer L, Waehendor C, Eisner DC, Knabe R (1992) Suitability of dehydrogenase activity assay as an index of soil biological activity. Biology and Fertility of Soils 16: $52-56$.

10. Alisi CS, Nwanyanwu CE, Akujobi and Ibegbulem CO (2008) Inhibition of dehydrogenase activity in pathogenic bacteria isolates by aqueous extracts of Musa paradisiaca (Var Sapientum). African Journal of Biotechnology 7: 1821-1825.

11. Zhao X, Li H, Wu Q, Li Y, Zhao C, et al. (2010) Analysis of dehydrogenase activity in phytoremediation of composite pollution sediment. $2^{\text {nd }}$ Conference on Environmental Science and Information Application Technology.

12. Mahmoud NS, Ghaly AE (2004) Influence of temperature and $\mathrm{pH}$ on the nonenzymatic reduction of triphenyltetrazolium chloride. Biotech Progr 20: 346-353.

13. Ruhlin A, Tyler G (1973) Heavy metal pollution and decomposition of spruce needle litter. Oikos 24: 402-416.

14. Rogers JE, Li SW (1985) Effect of metals and other inorganic ions on soil microbial activity: Soil dehydrogenase assay as a simple toxicity test. Bull Environ Contam Toxicol 34: 858-865.

15. Ghaly AE, Kok R, Ingrahm JM (1989) Growth rate determination of heterogeneous microbial population in swine manure. Appl Biochem Biotech 22:59-78.

16. Chander K, Brookes PC (1991) Is the dehydrogenase assay invalid as a method to estimate microbial activity in copper contaminated soils? Soil Bio Biochem 23: 909-915

17. Friedel JK, Molter K, Fischer WR (1994) Comparison and improvement of methods for determining soil dehydrogenase activity by using triphenyltetrazolium chloride and iodonitrotetrazolium chloride. Biol Fert Soils 18: 291-296.

18. Beloti V, Barros M, de Freitas JC, Nero LA, de Souza JA, et al (1998) Frequency of 2, 3, 5-triphenyltetrazolium chloride (TTC) non-reducing bacteria in pasteurized milk. Rev Microbiol 30: 137-140.

19. Olga P, Peta K, Jelena M, Srdjan R (2008) Screening method for detection of hydrocarbon-oxidizing bacteria in oil-contaminated water and soil specimens. J. Microbio Meth 74: 110-113.

20. Mahmoud NS (2005) Novel biotechnological approach for the production of chitin and de-icing agents. Ph.D Thesis, Dalhousie University.

21. Abdel-Fattah YR (2007) Application of fractional factorial design for the development of production media for the pikromycin macrolide family by Streptomyces venezuelae. Trends Applied Sci. Res 2: 472-482.

22. Glazebrook M, Doull JL, Stuttardan C, Vining LC (1990) Sporulation of Streptomyces venezuelae in submerged cultures. J. General Microbio 136: 581-588.

23. Green JD, Narahara HT (1980) Assay of succinate dehydrogenase activity by the tetrazolium method: Evaluation of an improved technique in skeletal muscle fractions. J Histochem Cytochem 28: 408-412.

24. Burton GA, Lanza GR (1986) Variables affecting two electron transport system assays. Appl. Environ. Microbiol 51: 931-937

25. Mahmoud NS, Ghaly AE (2006) Optimum condition for measuring dehydrogenase activity of Aspergillus niger using TTC. Ame J Bioche Biotech 2: 186-194

26. Tayler S, May E (2000) Investigation of the localization of bacterial activity on sandstone from ancient monuments. Int Biodeterior Biodegrad 46: 327-333.

27. Lee CW, Koopman B, Bitton G (1988) Evaluation of the formazan extraction step of INT-dehydrogenase assay. Toxic Assess 3: 41-54

28. Ghaly AE, Ben-Hassan RM (1993) Dehydrogenase activity measurement in yeast fermentation. App Biochem Biotech 43: 77-91.

29. Backor M, Fahselt D (2005) Tetrazolium reduction as an indicator of environmental stress in lichens and isolated bionts. Environ Exper Bot 53: 125-133.

30. Ghaly AE, Mahmoud NS (2006) Optimum conditions for measuring dehydrogenase activity of Aspergillus niger using TTC. Ame J Biochem Biotech 2: 186 194.

31. Mathew M, Obbard JP (2001) Optimization of dehydrogenase activity measurements in beach sediments contaminated with petroleum hydrocarbons. Biotech Lett 23: 227-230.

32. Trevors JT (1984) Effect of substrate concentration, inorganic nitrogen, O concentration, temperature and $\mathrm{pH}$ on dehydrogenase activity in soil. Plan So 77:285-293.

33. Breed RS (1957) Bergey's Manual of Determinative Bacteriology, $7^{\text {th }}$ edn, Williams and Wilkins Company, Baltimore, MD.

34. Doull JL, Ayer SW, Singh AK, Thibault P (1993) Production of a novel polyketide antibiotic, jadomycin $B$, by Streptomyces venezuelae following heat-shock. $J$ Antibiotics 46: 869-871. 